\title{
Design And Optimization of Injection Mould Tool
}

\author{
Ch.Neeraja ${ }^{1}$ Ch. Divya Bharathi ${ }^{2}$ \\ ${ }^{1,2}$ (Assistant professor, Mechanical Department, CMRTC, JNTUH, Hyderabad, Telangana, India)
}

\begin{abstract}
Air cooler works on the principle of heat loss during the evaporation process, resulting in cooler air. Cooler tank is one of the most important parts in water cooler's which stores the water. This project work deals with the optimization of injection mould to reduce cost, weight and to increase quality, the entire process will contain digital prototype, using pro-e, plastic advisor and ansys. Initially literature survey and data will be collected to understand methodology. Plastic flow analysis will be conducted to check the fill quality to reduce the manufacturing errors. Structural analysis will be conducted to recognize unwanted material to reduce wall thickness and change materials for unperformed parts to reduce costs weight. Thermal analysis will be conducted to optimize cooling channels for quality production. Milling/mould manufacturing method will be optimized to reduced time and effects.
\end{abstract}

Keywords: Air Cooler, Injection Moulding, Plastic Flow Analysis, Structural Analysis

\section{Introduction}

Air coolers also called evaporative coolers are used for cooling purposes. They are different from air conditioners in the sense air conditioners use refrigeration cycle principle whereas air coolers use the evaporation of water principle. There are five main evaporative cooler parts, with each of these being composed of other parts or pieces. The first part is the Blower which creates the airflow into and out of the cooler. Then there are the pads which filter and cool the air. These pads are attached to the side grill; this grill is supported with side grill pillars and a mounting stand for motor. And the final part is bottom tank used to store water. We have taken up the parameters of an already prepared air cooler and prepared a model for air cooler tank. And that mould tool is design done based on the model, by using Creo 2.0 (Pro/ Engineer) software. After determining the values of the mould tools, manufacturing drawings are prepared with full details selecting the appropriate materials. Subsequently, these mould tools are manufactured as per drawing prepared and subjected to quality control tests.

\section{Literature Review}

This thesis is devoted to analysis and optimization of the injection molding process with a focus on the mold. In the analysis, both process parameters and the design of the mold are taken in consideration. A procedure has been developed, i.e. a method and a program code, which enables optimization of different quantities, not only restricted to injection molding simulation, by altering different variables. There are many ways to interpret the word optimization". In this work, "optimization" means the use of mathematical algorithms in order to maximize or minimize any given quantity. This code, called Ver Opt, is written in Mat lab. It is versatile since it has the functionality of choosing different optimization routines, and it can make use of parallelization over TCP/IP and different external solvers. The software and different applications are further described in Paper A. There is a pocketful of software on the commercial market today, which enables the analysis of the injection molding process. One example is the software Moldex3D by Core tech System. By using simulation in the product development process, much can be gained since the software allows one to make most of the tedious and cost-consuming trial-and-errors in the virtual world, instead of on the shop floor.

\section{Drawing Of Cooler Tank}

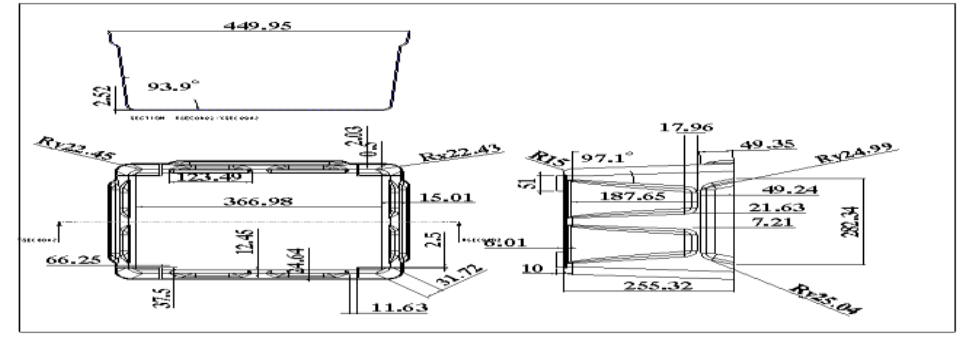

Fig. 1 The above image shows 2d drafting views along with dimensions of cooler tank

International Conference on Recent Innovations in Civil \& Mechanical Engineering

[i- CAM2K16] DOI: 10.9790/1684-16053043643 


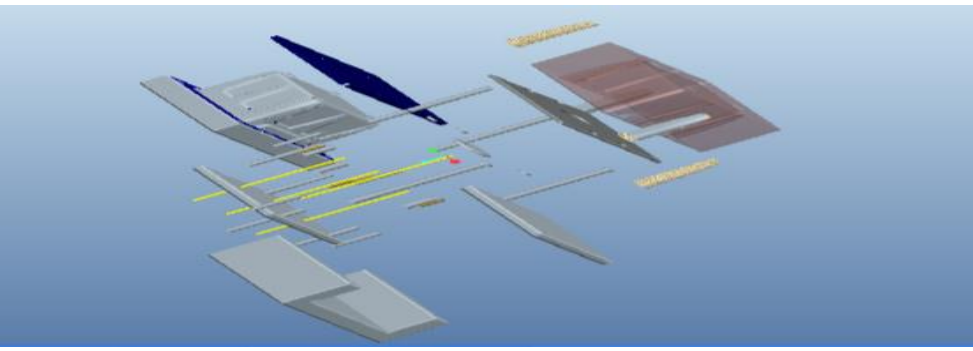

Fig. 2 The above image is showing die assembly

\section{Injection Moulding}

Injection moulding is a manufacturing process for producing parts from both thermoplastic and thermosetting plastic materials. Material is fed into a heated barrel, mixed, and forced into a mold cavity where it cools and hardens to the configuration of the mold cavity.

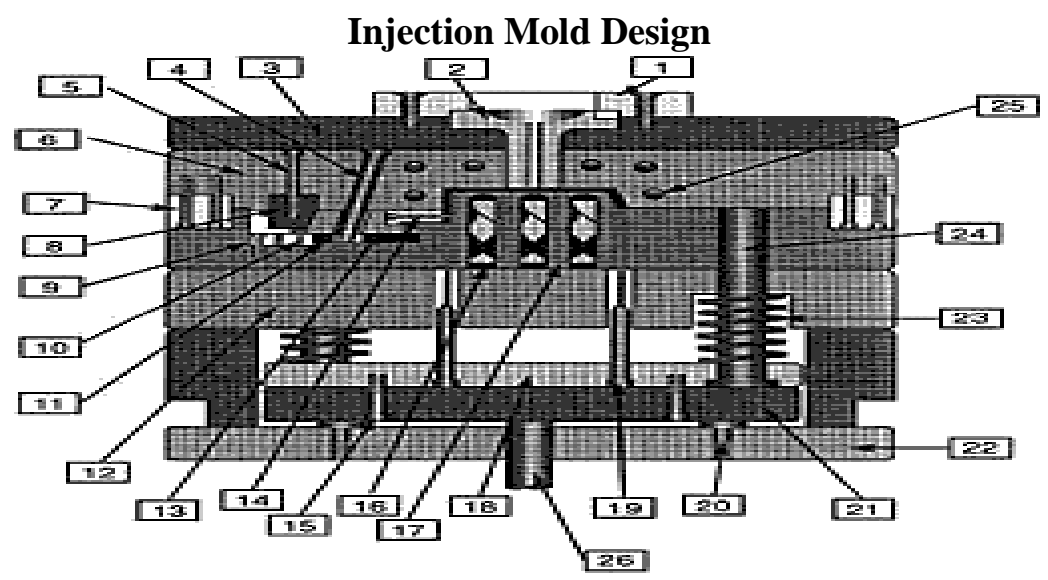

Fig. 3 Injection mould tool parts -

1. Locating Ring 2. Sprue Bushing 3. Top Clamping Plate 4. Angle Pin 5. Socket Head Bolt 6. A Plate 7. Guide Lock 8. Wedge Lock 9. Retainer 10. Dowel Pin 11. Wear Plate 12. Support Plate 13. Slide 14. Core Pin15. Socket Head Bolt 16. Baffle 17. '8' Plate 18. Ejector Retainer Plate 19. Ejector Pin 20. Stop Pin 21. Ejector Plate 22. Ejector Housing 23. Return Spring 24. Return Pin 25. Cooling Channel 26. Ejector Shaft

\section{Injections}

Plastic flow analysis - The Flow Analysis summary page gives an overview of the model's analysis, including information about actual injection time and pressure and whether weld lines and air traps are present. In addition, the dialog uses the Confidence of Fill result to assess the mould ability of the part.

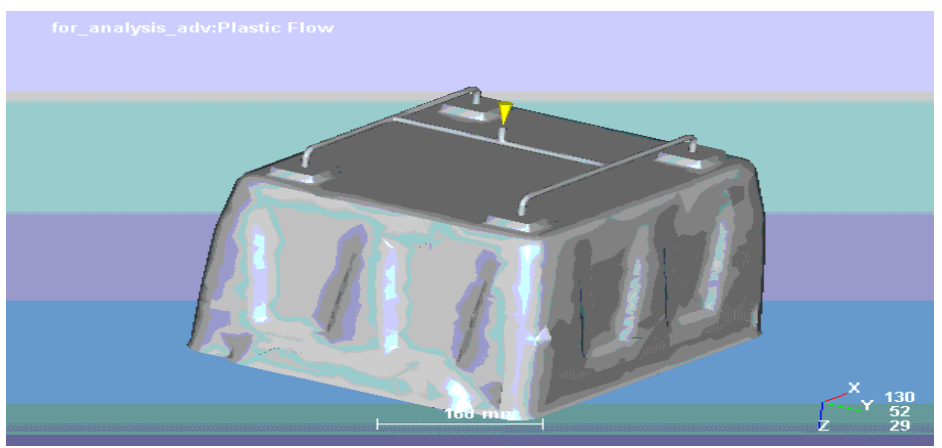

Fig. 4 Plastic flow analysis

Fill Time - This result shows the flow path of the plastic through the part by plotting contours which join regions filling at the same time. 


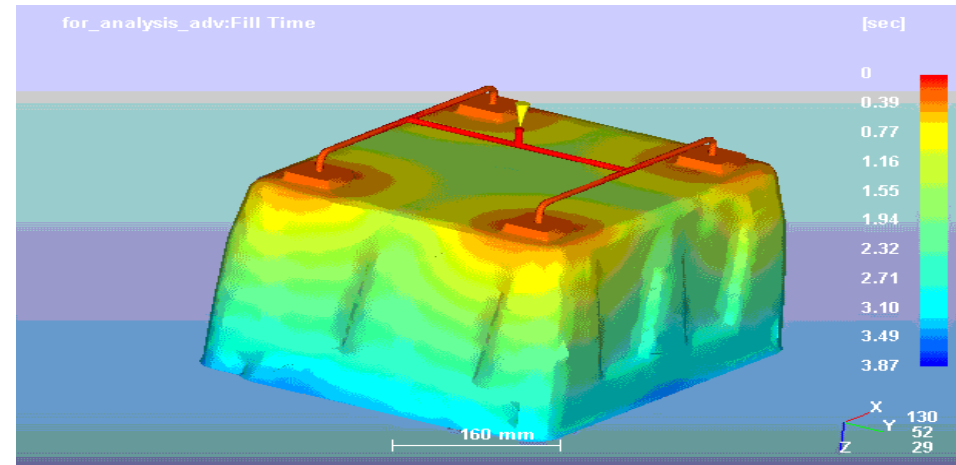

Fig. 5 Contour plot representation of plastic flow path

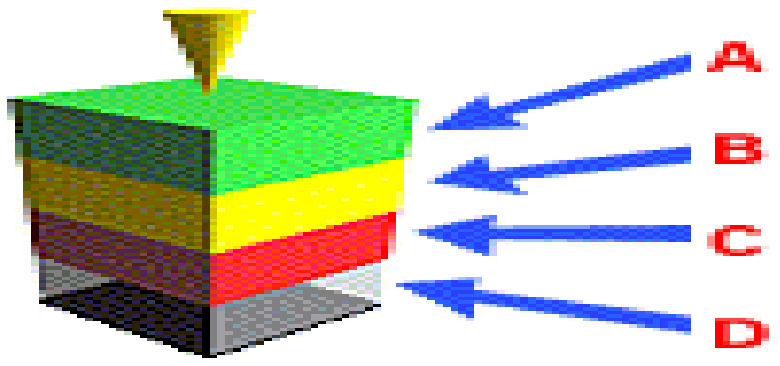

Fig. 6 Material filling regions of the tool - A: will definitely fill B: may be difficult to fill or may have quality problems C: may be difficult to fill or may have quality problems D: will not fill (short shot).

\section{Pressure Results Derivation}

At any point during Filling, there is a pressure gradient from a maximum value at the injection location down to atmospheric pressure at the flow front. The Adviser calculates this pressure distribute on continuously throughout cavity filling and presents you with 2 pressure results considered with reference to the following simple part that has a single polymer injection location at one end: The following graph shows how pressure varies over time at both the polymer injection location and at the point marked $\mathbf{X}$.

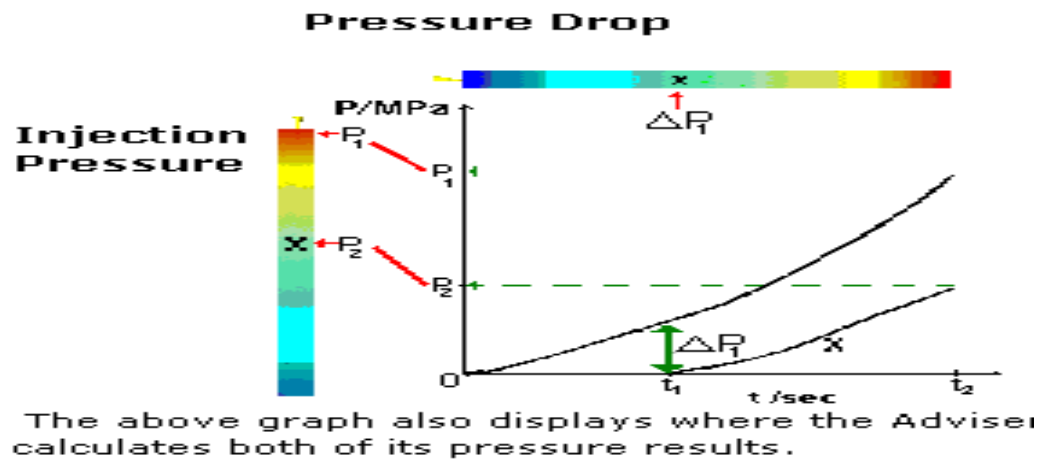

Fig. 7 The above graph also displays where the Adviser calculates both of its pressure results.

The Pressure Drop result is a contour plot showing the pressure required to flow material to each point in the cavity. The value calculated is the pressure at the injection location as a point ( $\mathrm{X}$ in our example) fills and this value is plotted at the point corresponding to $\mathrm{X}$ on the model. Unlike the Injection Pressure result, the Pressure Drop is not displayed for any one moment in time. The values displayed relate to the time that the location in question (X) actually filled. The Injection Pressure result is a contour plot of the pressure distribution throughout the cavity at the end of filling. This is effectively a "snapshot" at one instant of time. The maximum value is at the Injection Location and the minimum is at the last point of the cavity to fill 


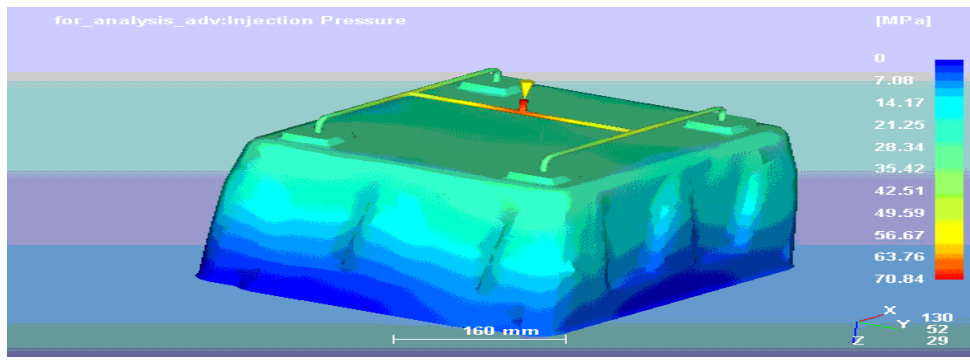

Fig. 8 Injection pressure

Flow Front Temperature - The flow front temperature result uses a range of colors to indicate the region of lowest temperature (colored blue) through to the region of highest temperature (colored red). The colors represent the material temperature at each point as that point was filled. The result shows the changes in the temperature of the flow front during filling.

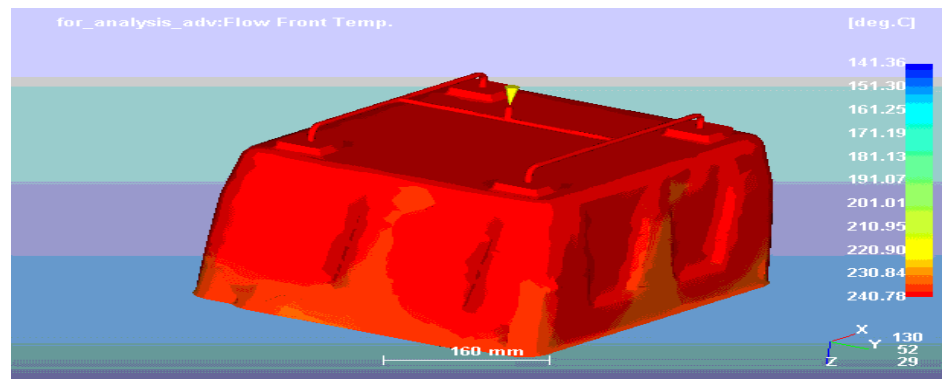

Fig. 9 Flow front temperature

The Injection Pressure result is a contour plot of the pressure distribution throughout the cavity at the end of filling. This is effectively a "snapshot" at one instant of time. The maximum value is at the Injection Location and the minimum is at the last point of the cavity to fill

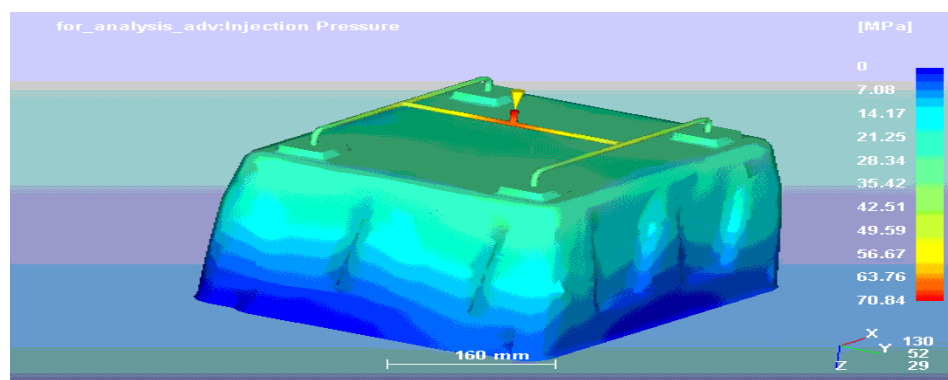

Fig. 10 Injection pressure

Flow Front Temperature - The flow front temperature result uses a range of colors to indicate the region of lowest temperature (colored blue) through to the region of highest temperature (colored red). The colors represent the material temperature at each point as that point was filled. The result shows the changes in the temperature of the flow front during filling.

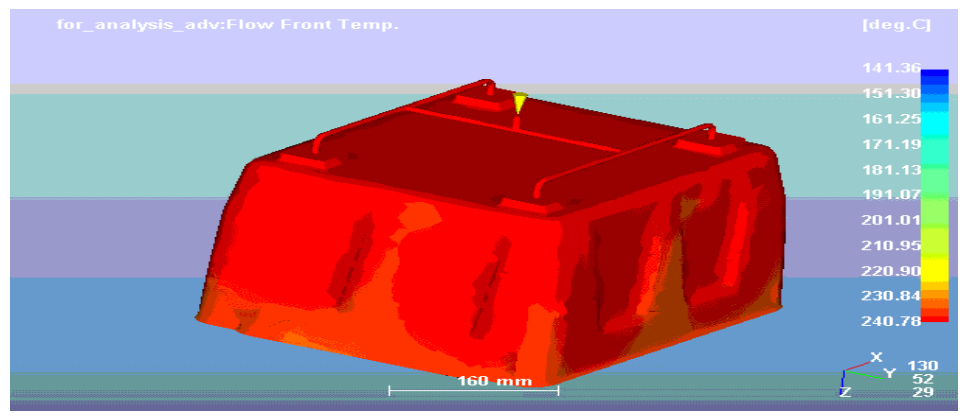

Fig. 11 Flow Front Temperature 
Quality Analysis - The Quality display is derived from combinations of the five results listed below. These five results are each divided into ranges - unacceptable (red), acceptable (yellow) and preferred (green). The five results are:

- flow front temperature

- $\quad$ pressure drop

- cooling time

- shear rate

- $\quad$ shear stress

For each area of the cavity, the five results are evaluated. If all five results in an area are acceptable, the area is green. If there is at least one unacceptable result, the area is red. If there are both acceptable and preferred results, the area is yellow

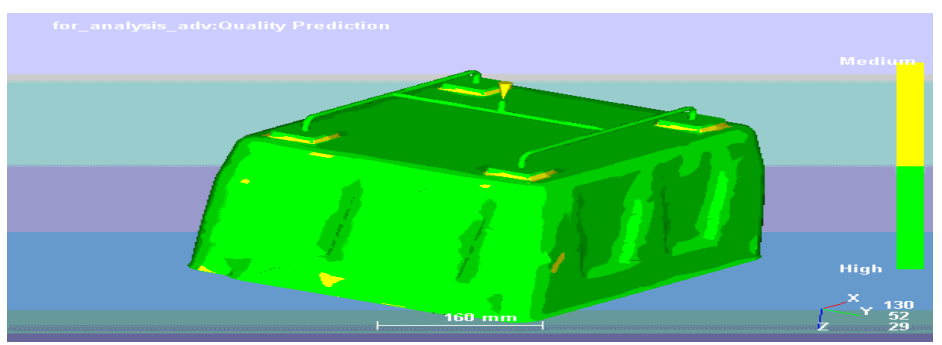

Fig. 12 Area of the cavity

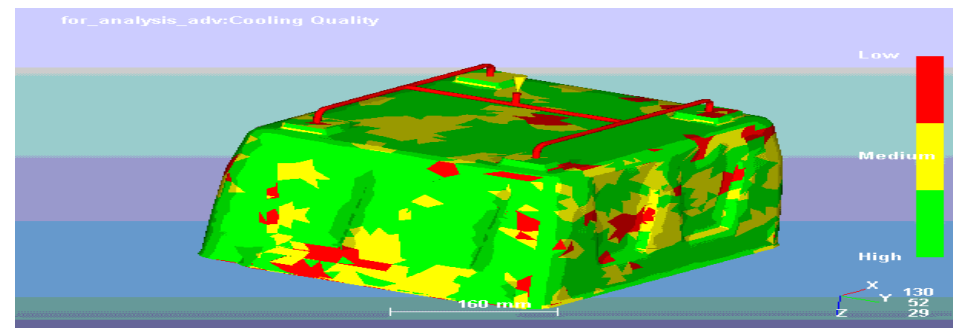

Fig. 13 Adv cooling quality

\section{Introduction To Ansys}

ANSYS is general-purpose finite element analysis (FEA) software package. Finite Element Analysis is a numerical method of deconstructing a complex system into very small pieces (of user-designated size) called elements. The software implements equations that govern the behavior of these elements and solves them all; creating a comprehensive explanation of how the system acts as a whole. These results then can be presented in tabulated or graphical forms. This type of analysis is typically used for the design and optimization of a system far too complex to analyze by hand. Systems that may fit into this category are too complex due to their geometry, scale, or governing equations.

\section{Overview Of Structural Analysis}

Structural analysis is probably the most common application of the finite element method. The term structural (or structure) implies not only civil engineering structures such as bridges and buildings, but also naval, aeronautical, and mechanical structures such as ship hulls, aircraft bodies, and machine housings, as well as mechanical components such as pistons, machine parts, and tools.

\section{Structural Analysis Of Standard Mould}

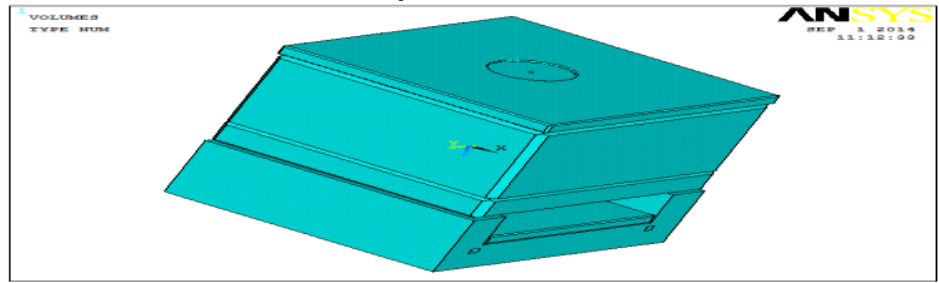

Fig. 14 The above image is the imported model of composite shaft. Modeling was done in Pro-E and imported with the help of IGES (Initial Graphical Exchanging Specification). 
Element Type: Solid 20 node 95 (EN 36)

Material Properties: Young's Modulus (EX) : 20900N/mm²

Poisson Ratio (PRXY): 0.27

Density: $0.000007870 \mathrm{~kg} / \mathrm{mm}^{3}$

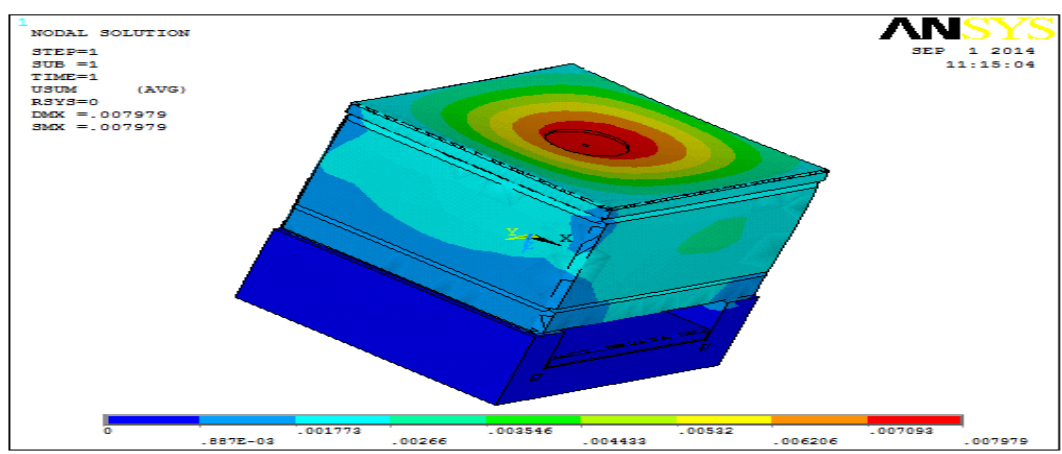

Fig. 15 The above image shows the displacement, value is $0.007979 \mathrm{~mm}$

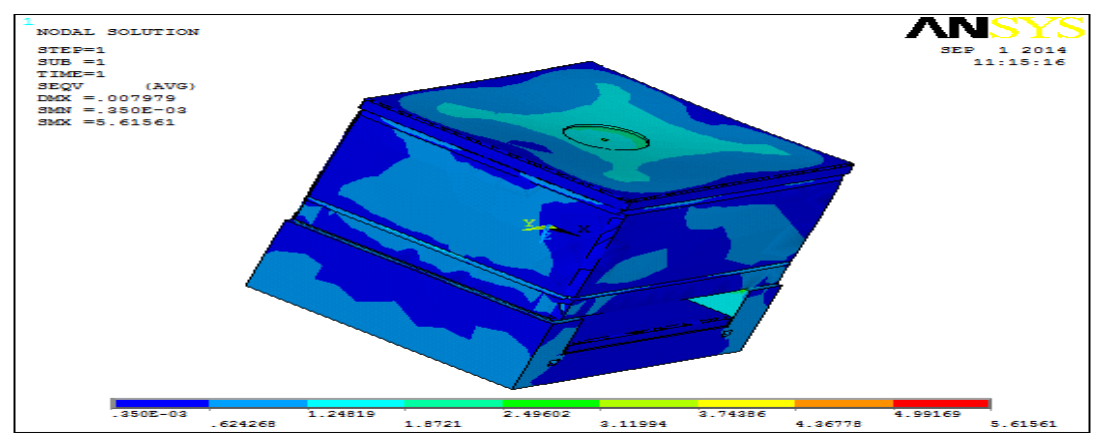

Fig. 16 The above image shows the stress, value is $5.61561 \mathrm{~N} / \mathrm{mm}^{2}$

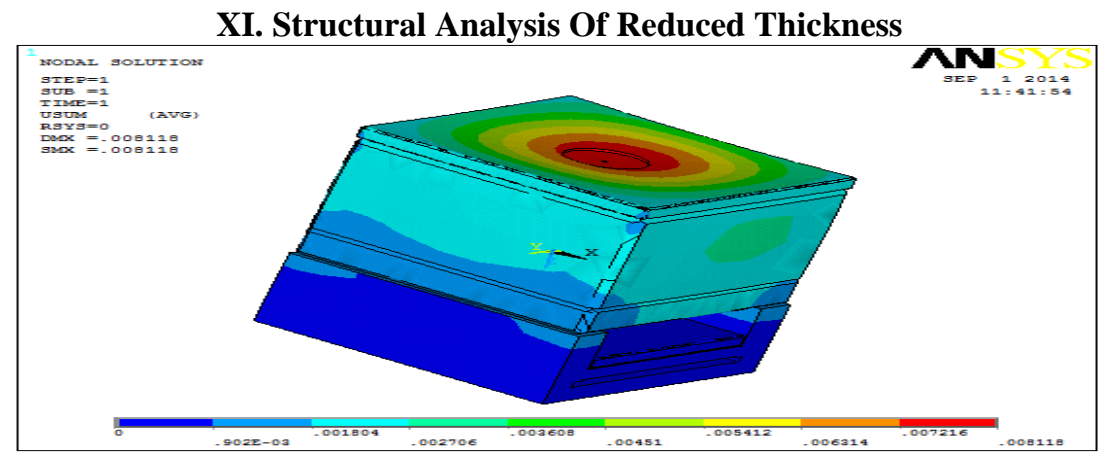

Fig. 17 The above image shows the displacement, value is $0.008118 \mathrm{~mm}$

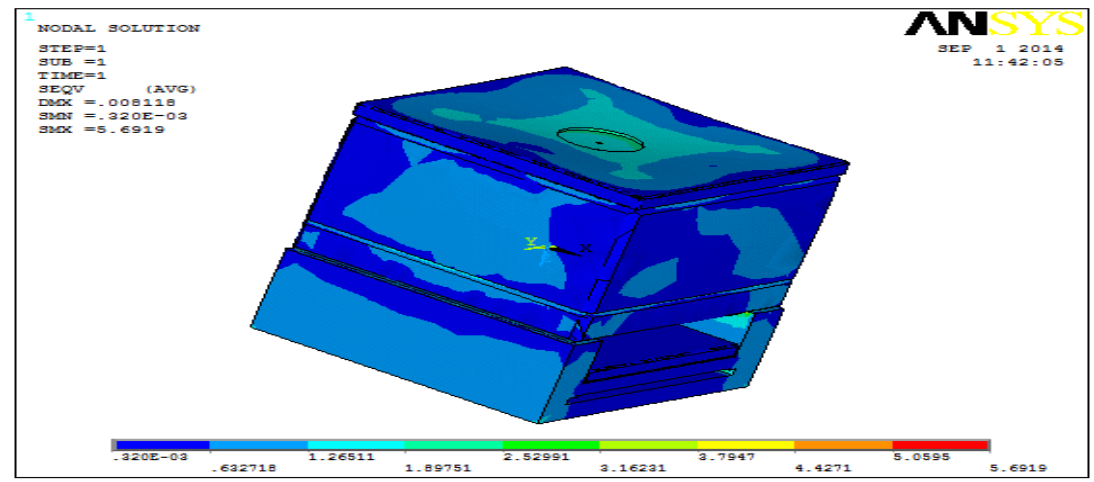

Fig. 18 The above image shows the stress, value is $5.6919 \mathrm{~N} / \mathrm{mm}^{2}$ 


\section{Structural Analysis Of Reduced Thickness Two}

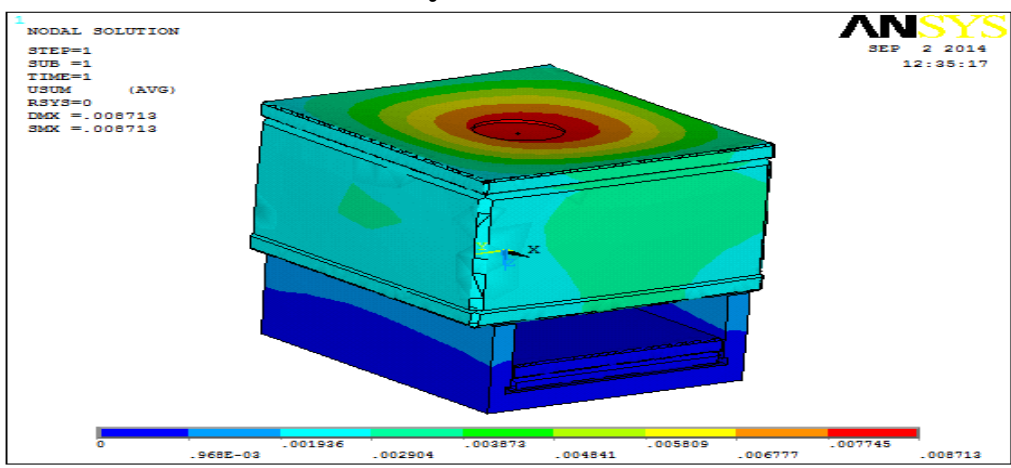

Fig. 19 The above image shows the displacement, value is $0.008713 \mathrm{~mm}$

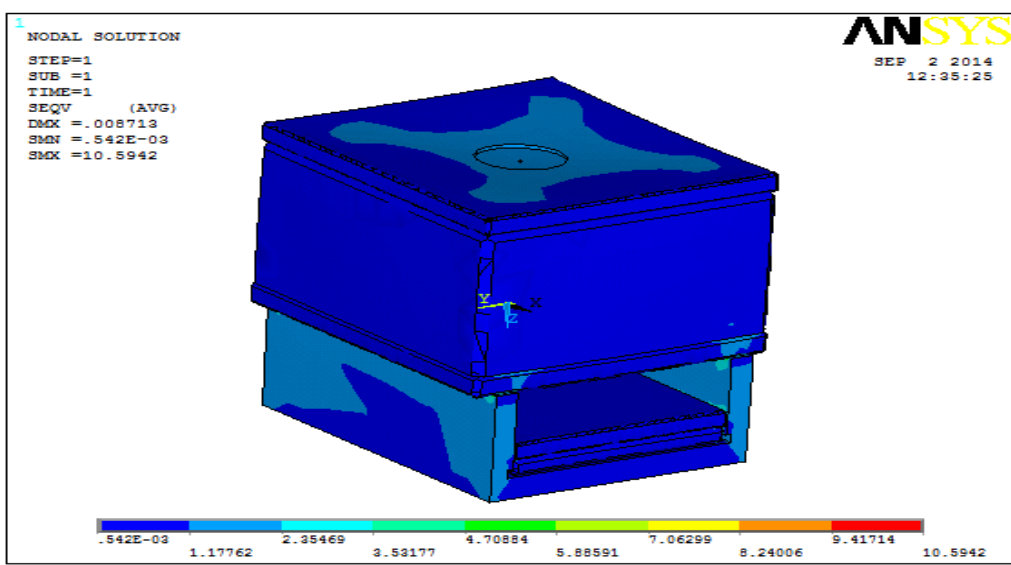

Fig. 20 The above image shows the stress, value is $10.5942 \mathrm{~N} / \mathrm{mm}^{2}$

XIII. Analysis Result Table

Table 1 Structural analysis

\begin{tabular}{|c|c|c|}
\hline & $\begin{array}{c}\text { Displacement } \\
\text { in mm }\end{array}$ & $\begin{array}{c}\text { Stress } \\
\text { In N/mm }\end{array}$ \\
\hline Standard mold & 0.007979 & 5.61561 \\
\hline Reduced thickness & 0.008118 & 5.6919 \\
\hline Reduced thickness two & 0.008713 & 10.5942 \\
\hline
\end{tabular}

Time For Machaining Processes

Cavity roughing process $=209397.32 \mathrm{sec}$

Finishing process time $=17337.18$ sce

Total time $63 \mathrm{hrs}$

Core roughing process time 586735.8 se

Core finishing time $16011.62 \mathrm{sec}$

Total time $167 \mathrm{hrs}$

Overall cost: 230 (hours) $* 300$ (per hour) $=$ Rs 69,000

Table 2 Weight and cost table for existing model

\begin{tabular}{|c|c|c|r|}
\hline Index & Material Name & Quantity \& Price & Cost \\
\hline Bolts & C22 Carbon Steel Alloy & $1.516 \mathrm{~kg} \mathrm{X} 275 \mathrm{Rs}$ & $416.00 /-$ \\
\hline Plates & Ms Tool Grade & $754.67 \mathrm{Kg}$ X175 Rs & $1,32,067.00 /-$ \\
\hline Die Set (Core\& Cavity) & Hardened Steel & $884.69 \mathrm{~kg}$ X 375 Rs & $331758.75 /-$ \\
\hline Guide Pins & Ohns & 7.508 X 325 Rs & $2460.00 /-$ \\
\hline Guide Sleeves & Guide Sleeves & 6 nos X 500rs & $3000.00 /-$ \\
\hline Guide Pillers & Guide Pillers & 6 X 1300rs & $7800 /-$ \\
\hline Water Inlet Knobs & Water Inlet Knobs & 12 X150 Rs & $3600 /-$ \\
\hline \multicolumn{4}{|c}{ Total } \\
\hline
\end{tabular}


Table 3 Weight and cost table for reduced thickness 1

\begin{tabular}{|l|c|c|c|}
\hline Index & Material Name & Quantity \& Price & Cost \\
\hline Bolts & $\begin{array}{c}\text { C22 Carbon Steel Alloy For } \\
\text { Bolts }\end{array}$ & $1.516 \mathrm{~kg}$ X275 Rs & $416.00 /-$ \\
\hline Plates & Ms Tool Grade & $700.40 \mathrm{Kg}$ X175 Rs & $1,22,570.00 /-$ \\
\hline $\begin{array}{l}\text { Die Set (Core\& } \\
\text { Cavity) }\end{array}$ & Hardened Steel & $884.69 \mathrm{~kg} \mathrm{X} \mathrm{375} \mathrm{Rs}$ & $331758.75 /-$ \\
\hline Guide Pins & Ohns & 7.508 X 325 Rs & $2460.00 /-$ \\
\hline Guide Sleeves & Guide Sleeves & 6 nos X 500rs & $3000.00 /-$ \\
\hline Guide Pillers & Guide Pillers & $12 \times 150 \mathrm{Rs}$ & $7800 /-$ \\
\hline Water Inlet Knobs & Water Inlet Knobs & $3600 /-$ \\
\hline Total & $4,71,604.75 /-$ & \\
\hline
\end{tabular}

Table 4 Weight and cost table for reduced thickness 2

\begin{tabular}{|c|c|c|c|}
\hline Index & Material Name & Quantity \& Price & Cost \\
\hline Bolts & C22 Carbon Steel Alloy & $1.516 \mathrm{~kg} \mathrm{X275} \mathrm{Rs}$ & $416.00 /-$ \\
\hline Plates & Ms Tool Grade & $646.60 \mathrm{Kg} \mathrm{X175} \mathrm{Rs}$ & $1,13,155.00 /-$ \\
\hline $\begin{array}{l}\text { Die Set (Core\& } \\
\text { Cavity) }\end{array}$ & Hardened Steel & $884.69 \mathrm{~kg} \mathrm{X} \mathrm{375} \mathrm{Rs}$ & $331758.75 /-$ \\
\hline Guide Pins & Ohns & 7.508 X 325 Rs & $2460.00 /-$ \\
\hline Guide Sleeves & Guide Sleeves & 6 nos X 500rs & $3000.00 /-$ \\
\hline Guide Pillers & Guide Pillers & 6 X 1300rs & $7800 /-$ \\
\hline Water Inlet Knobs & Water Inlet Knobs & 12 X150 Rs & $3600 /-$ \\
\hline \multicolumn{2}{|r}{ Total } & $4,62,189.75 /-$ \\
\hline
\end{tabular}

490000

480000

470000

460000

450000

1

Fig. 20 Result analysis
Series1

reduced thk 1

reduced thk 2

\section{Conclusion}

In this project, an air cooler water tank as per the parameters with tank capacity 15 liters, width $380 \mathrm{~mm}$, length $420 \mathrm{~mm}$, and height $260 \mathrm{~mm}$ is designed..Core and Cavity is extracted for the tank. Die design is prepared for the same. The modeling, core-cavity extraction and die design is done in PRO/ENGINEER. Mould Flow Analysis is done on water tank. Mould flow analysis for finding the material filling, pressure distribution, air traps, and wild lines formed during injection moulding process. Mould Flow Analysis is done using "Plastic Advisor" which is a module in Pro/Engineer. By simulating the plastic-filling process for injection-moulded parts, Creo 2.0 (Pro/ENGINEER) Plastic Advisor enables engineers to design for manufacturability, uncover problems, and propose remedies, reducing development time and expense. By using this process manufacture of air cooler tank can be done without any failures. Static and thermal analysis is conducted on mould structure for weight reduction and for optimized cooling channels.

- As per the analytical results reduction of spacer housing thickness and reduction of core back support is also performing well, so better to use reduced thickness 2 model for the cost and weight reduction.

- $\quad$ By reducing plate sizes company can reduce up-to the Rs.19,000/-

(1) Sundararajamoorthy T.V. Machine design,

\section{References}

(2) Khurmi R.S./ Guptha J.K. Machine design, (S.CHAND)

(3) Design data book: P.S.G. College of Technology (Kalaikathirachchagam),

(4) Injection Mold Design Engineering David O.Kazmer

(5) Composite Technology Lengsfeld H.,Wolff-Fabris,F., Kramer

International Conference on Recent Innovations in Civil \& Mechanical Engineering

[i- CAM2K16] DOI: 10.9790/1684-16053043643

43 | Page 